\title{
Verrucous carcinoma and squamous cell papilloma of the oral cavity: Report of two cases and review of literature
}

\author{
Hilal Alan ${ }^{1}$, Serkan Agacayak², Gulten Kavak², Ayse Ozcan ${ }^{1}$
}

Correspondence: Dr. Hilal Alan

Email: hilalturker@hotmail.com
'Department of Oral and Maxillofacial Surgery, University of Inonu, Malatya, Turkiye,

${ }^{2}$ Department of Oral and Maxillofacial Surgery, University of Dıcle, Diyarbakır, Turkiye

\section{ABSTRACT}

Verrucous carcinoma (VC) of oral cavity is a rare variant of well-differentiated squamous cell carcinoma and squamous papilloma is a benign proliferation of the stratified squamous epithelium, which results in a papillary or verrucous exophytic mass. There is a certain clinical similarity between squamous cell papilloma and VC. We presented a report of two cases which are VC and squamous cell papilloma that are showed the same clinical appearance but different pathological appearance, with a review of the literature.

Key words: Oral cavity, squamous cell papilloma, verrucous carcinoma

\section{INTRODUCTION}

Oral verrucous carcinoma (VC), as defined by Ackerman, is a rare, nonmetastasizing, well-differentiated variant of oral squamous cell carcinoma (SCC)..$^{[1]}$ Although VC has a slow and continuous local growth pattern; patients with VC have an excellent prognosis. ${ }^{[2]} \mathrm{VC}$ is occasionally developed in the oral cavity, ${ }^{[2,3]}$ though it may be found on other anatomic sites including the sinus, larynx, paranasal sinuses, pyriform esophagus, nasal cavity, lacrimal duct, external auditory meatus, vagina, rectum, penis, soles of the feet and bladder. ${ }^{[4]}$ In current literature, the most common sites of oral mucosal involvement are the buccal mucosa, followed by the mandibular alveolar crest, gingiva, and tongue. These VC lesions in the oral cavity typically appear as a painless, broad-based, well-circumscribed, thick white plaque resembling a cauliflower. The lesions may be white, pink or erythematous. Lymph node involvement and distant metastasis are rare in VC. ${ }^{[3,5,6]} \mathrm{VC}$ occurs more frequently in males over the sixth decade. ${ }^{[5,6]}$ Histopathologic and clinical diagnosis of oral VC may be difficult, so close cooperation between pathologist and surgeon is required in order to identify the nature of the lesion. ${ }^{[7]}$ The etiology of oral VC is unclear; risk factors include smoking, chewing tobacco, alcohol use, and poor oral hygiene, ${ }^{[8-10]}$ but it is reported that $15-51 \%$ of oral VCs are found in individuals without these habits. ${ }^{[11]}$ Other etiologic factors include immunosuppression, human papillomavirus (HPV), and other viruses. The treatment of oral VC remains controversial. Surgery, chemotherapy, radiotherapy, or a combination of procedures has been used in the treatment of VC. ${ }^{[12-14]}$ The rate of local recurrences ranges from $30 \%$ to $50 \% .{ }^{[15]}$

Oral squamous papillomas are papillary or verrucous exophytic lesions of the oral cavity ${ }^{[16]}$ caused by HPV, usually HPV-6 or HPV-11. ${ }^{[17]}$ They involve a benign proliferation of the stratified squamous epithelium and occur most frequently on the hard and soft palate, uvula, tonsil, or epiglottis, but any surface of the oral cavity can be affected. ${ }^{[16,18]}$ These lesions are often asymptomatic and tend to progress slowly. Oral squamous papillomas could mimic condyloma acuminatum, VC, or exophytic

This is an open access article distributed under the terms of the Creative Commons Attribution-NonCommercial-ShareAlike 3.0 License, which allows others to remix, tweak, and build upon the work non-commercially, as long as the author is credited and the new creations are licensed under the identical terms.

For reprints contact: reprints@medknow.com

How to cite this article: Alan H, Agacayak S, Kavak G, Ozcan A. Verrucous carcinoma and squamous cell papilloma of the oral cavity: Report of two cases and review of literature. Eur J Dent 2015;9:453-6.

DOI: $10.4103 / 1305-7456.163224$ 
carcinoma because their clinical appearance is similar. Surgical removal with laser ablation, electrocautery, intralesional injections of interferon, cold-steel excision, and cryosurgery have been used in the treatment of oral squamous papillomas. ${ }^{[16,19-21]}$

There is a certain clinical resemblance between squamous cell papilloma and VC. We present two cases, one of a squamous papilloma, and the other of a VC in the form of oral lesions, both treated with a surgical excision.

\section{CASE REPORTS}

\section{Case 1}

A 65-year-old male was admitted to the Department of Oral and Maxillofacial Surgery, Dicle University, Diyarbakir, Turkey for an evaluation of a verrucous white lesion in the oral cavity. The patient's medical history revealed no systemic diseases. The patient had been smoking for many years. Intraoral examination showed the presence of a wide, white, verrucous lesion on the left buccal mucosa. The lesion was a cauliflower-shaped exophytic lesion with a dimension of $2.5 \mathrm{~cm} \times 1 \mathrm{~cm}$ [Figure 1a]. According to the patient, the lesion had been present for approximately 5 years and had been slowly growing over the previous 2 months. The patient had experienced no pain or other symptoms. An extraoral examination revealed that the lymph nodes in the head and neck region were clinically normal. Local anesthesia was given around the lesion, and the exophytic portion of the lesion was completely excised for biopsy and sent for histopathological examination with a prediagnosis of papilloma. After histopathological examination of the excisional biopsy specimen, a diagnosis of VC was made [Figure $2 \mathrm{a}$ and $\mathrm{b}$ ]. The clinical follow-up showed complete tissue healing, and no recurrence had been seen at the 1-year follow-up [Figure 1b].

\section{Case 2}

A 44-year-old male was admitted to the Department of Oral and Maxillofacial Surgery, Dicle University, Diyarbakir, Turkey with a painless mass on the palate. Intraoral examination revealed a pedicle exophytic lesion on the hard and soft palate border, whitish in color, with a pebbled surface, approximately $5 \mathrm{~mm} \times 3 \mathrm{~mm}$ in size [Figure 3a]. He did not have any specific habit that could be considered a source of local irritation of the area. Local anesthesia was given around the lesion, which was then completely excised from its connection to the palate. The histopathological assessment of the lesion revealed a papillary mucosal mass surrounded by parakeratinised stratified squamous epithelium of varying thickness, with a papillary surface and exocytosis [Figure 3b]. The oral pathology report confirmed our preintervention diagnosis of squamous cell papilloma. The clinical follow-up showed complete tissue healing. A 1-year follow-up was performed, and there was no evidence of recurrence of the lesion [Figure 3c].

\section{DISCUSSION}

Cancer is a major problem for public health, and oral cancer is among the 10 most common cancers worldwide. ${ }^{[22]}$ Among these oral cancers, SCC is the most common malignant neoplasm in the oral cavity. ${ }^{[23]}$ Oral VC is a rare, well-differentiated

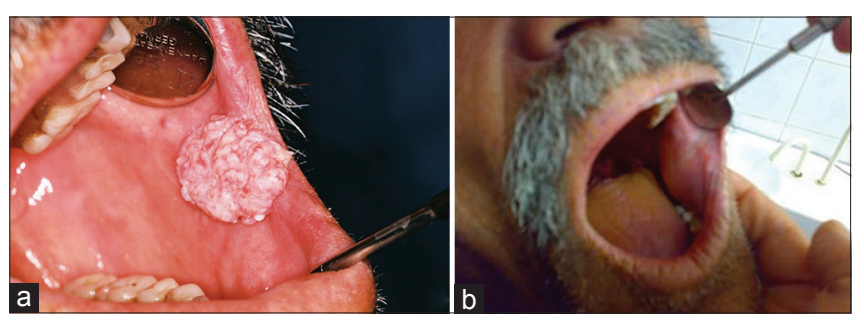

Figure 1: (a) The clinical photograph of verrucous carcinoma in the buccal mucosa (b) 1-year postoperative view of the buccal mucosa

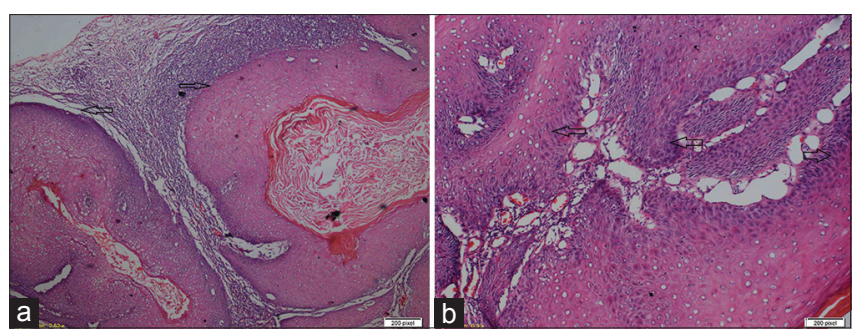

Figure 2: (a) Verrucous carcinoma showing pushing border (arrows, $\mathrm{HE}, \times 40)(\mathrm{b})$ minimal cytological atypia consistent with verrucous carcinoma (arrows, HE, $\times 100$ )

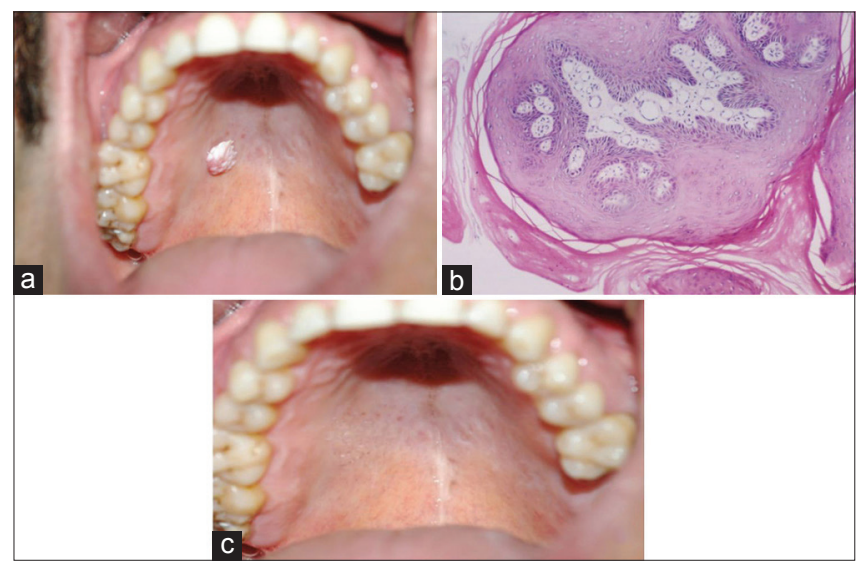

Figure 3: (a) The clinical photograph of squamous cell papilloma in the oral cavity (b) histopathological appearance of squamous cell papilloma $(\mathrm{HE}, \times 41)(\mathrm{c}) 1$-year postoperative view of the hard palate 
variant of SCC. ${ }^{[24]}$ Oral squamous papillomas are common benign epithelial neoplastic lesions which are generally solitary and its biological potential for malignant transformation is still a matter of debate. ${ }^{[20]}$

VC has been reported in the literature under a variety of terms, including florid oral papillomatosis, Ackerman's tumor, epithelioma cuniculatum, Buschke-Loewenstein tumor, cutis papillomatosis carcinoides of Gottron, and carcinoma cuniculatum. ${ }^{[25]} \mathrm{VC}$ occurs more frequently in elderly men over 60 , and the incidence of $\mathrm{VC}$ varies from $4.5 \%$ to $9 \% .{ }^{[26]}$ Oral squamous papillomas commonly occur between age 30 and 50 years, and sometimes can occur before the age of 10 years. These lesions account for $8 \%$ of all oral tumors in children. ${ }^{[27]}$

The pathogenesis of $\mathrm{VC}$ of the oral cavity is not clear. HPV, chewing tobacco, alcohol use, use of snuff, and poor oral hygiene are predisposing factors for the development of VC of the oral cavity. ${ }^{[8-10]} \mathrm{HPV}$ types six and 11 are the most common pathogens for oral squamous papillomas, but there is controversy regarding its viral origin. ${ }^{[18]}$

In the oral cavity, VC occurs on buccal mucosa, gingival and alveolar ridge. Predominantly being a squamous mucosal lesion, VC may also be found on cutaneous surfaces. Macroscopically, these VC lesions in the oral cavity appear to show a broadly implanted, exophytic cauliflower growth, well-circumscribed and with a locally invasive character. ${ }^{[4]}$ Intraorally, oral squamous papillomas are found most commonly on the palate (which was observed in the case reported here), lips, buccal mucosa, gingiva, and tongue but any region of the oral cavity could be impressed, such as the uvula, epiglottis, or tonsil. ${ }^{[16,18]}$ These lesions generally measure less than $1 \mathrm{~cm}$ in the largest dimension and appear as pink to white exophytic granular or cauliflower-like surface alterations and may be pedunculated or sessile in the configuration. The lesions are generally asymptomatic, as in the present case, although Devi et al. ${ }^{[18]}$ and Goodstein et al. ${ }^{[21]}$ reported two cases of a squamous papilloma of the uvula that atypically produced symptoms. Squamous papillomas are divided into two forms: Isolated-solitary and multiple-recurring. The isolated-solitary type generally appears in adults, as in the present case. Patients who are infected with the human immunodeficiency virus (HIV) frequently have multiple oral lesions. Malignant transformation of a papilloma is more common in the multiple-recurring type. ${ }^{[20]}$

Microscopically, VC has epithelial proliferation with downgrowth of epithelium into connective tissue but usually without the pattern of true invasion. The epithelium is well differentiated and shows little mitotic activity, pleomorphism or hyperchromatism. Cleft like spaces lined by a thick layer of parakeratin extend from the surface deep into the lesion. Parakeratin plugging also occurs in the epithelium. Parakeratin lining of clefts with parakeratin plugging is the hallmark of VC. Chronic inflammatory cell infiltration in the underlying connective tissue may or may not be present. ${ }^{[4,5,28]}$ In addition, all rete pegs of the epithelium tend to project into the underlying connective tissue, at more or less the same level and this is called as "pushing border." $[4,28]$ Squamous papilloma presents as many long, thin and finger-like projections extending above the mucosal surface. Each finger-like projection is lined by stratified squamous epithelium and contains a central connective tissue. The spinous cells proliferate in a papillary pattern. Koilocytes-HPV altered cells may be observed. The upper epithelial cells show pyknotic and crenated nuclei, often surrounded by edematous or optically clear zone, the so-called "koilocytic" cell. Chronic inflammatory cells are also observed. ${ }^{[20]}$

An accurate diagnosis of oral VC could be challenging and requires an adequate biopsy specimen. ${ }^{[7]}$ Diagnosis also requires experience and close collaboration between surgeon and pathologist. These lesions have a tendency to mimic benign tumors of the oral cavity. ${ }^{[29]}$ For this reason, the differential diagnosis should include lesions of similar appearance such as verrucous hyperplasia, papilloma, proliferative verrucous leukoplakia, pseudoepitheliomatous hyperplasia, SCC, chronic candidiasis, and condyloma accuminatum. ${ }^{[29,30]}$ In Case 1, reported above, the initial diagnosis was squamous papilloma, and after histopathogical examination it was identified as a VC. The differential diagnosis of oral squamous papilloma, when solitary, includes verruciform xanthoma, papillary hyperplasia, and condyloma acuminatum. In addition, multiple squamous papillomas would consider focal epithelial hyperplasia (Heck disease). ${ }^{[20]}$

Wide surgical excision is considered the primary choice of treatment for VC. Some studies recommend that the anaplastic transformation of the VC can occur after radiotherapy, and hence radiotherapy in combination with surgery is rarely performed. ${ }^{[31]}$ Radiotherapy might be the second treatment choice for VC when surgery is not correctly possible. Regarding chemotherapy, Tanaka et al. ${ }^{[32]}$ have reported the effectiveness of preoperative chemotherapy for advanced VC of the tongue. Recently, treatment of a VC with an intra-arterial infusion of methotrexate ${ }^{[12,13,33]}$ and topical 5-aminolevulinic acid-mediated photodynamic therapy 
was reported. ${ }^{[34]}$ Although the lesion has an excellent prognosis, local recurrences may develop. Furthermore, neck dissection is not necessary because lymph node metastases are extremely rare. ${ }^{[4,35]}$ The procedure for oral papilloma diagnosis is mainly clinical, followed by cytology and then proceed by biopsy. ${ }^{[36]}$ Surgical removal is the preferred treatment, and laser ablation, electrocautery, intralesional injections of interferon, cold-steel excision, and cryosurgery have all been used in the treatment of oral squamous papillomas. ${ }^{[16,19,20,21]}$ Recurrence of squamous papilloma is rare except for lesions in patients infected with HIV. ${ }^{[16]}$

\section{CONCLUSIONS}

The clinical diagnosis of $\mathrm{VC}$ and squamous cell papilloma is obviously important, but these two lesions can be difficult to distinguish from other lesions of similar appearance. Precise diagnosis, therefore, depends on careful collaboration between the surgeon and the pathologist.

\section{Financial support and sponsorship Nil.}

\section{Conflicts of interest}

There are no conflicts of interest.

\section{REFERENCES}

1. Ackerman LV. Verrucous carcinoma of the oral cavity. Surgery 1948;23:670-8

2. Rekha KP, Angadi PV. Verrucous carcinoma of the oral cavity: A clinico-pathologic appraisal of 133 cases in Indians. Oral Maxillofac Surg 2010;14:211-8.

3. Koch BB, Trask DK, Hoffman HT, Karnell LH, Robinson RA, Zhen $\mathrm{W}$, et al. National survey of head and neck verrucous carcinoma: Patterns of presentation, care, and outcome. Cancer 2001;92:110-20.

4. Ferlito A, Recher G. Ackerman's tumor (verrucous carcinoma) of the larynx: A clinicopathologic study of 77 cases. Cancer 1980;46:1617-30.

5. Oliveira DT, de Moraes RV, Fiamengui Filho JF, Fanton Neto J, Landman G, Kowalski LP. Oral verrucous carcinoma: A retrospective study in São Paulo Region, Brazil. Clin Oral Investig 2006;10:205-9.

6. Walvekar RR, Chaukar DA, Deshpande MS, Pai PS, Chaturvedi P, Kakade A, et al. Verrucous carcinoma of the oral cavity: A clinical and pathological study of 101 cases. Oral Oncol 2009;45:47-51.

7. McDonald JS, Crissman JD, Gluckman JL. Verrucous carcinoma of the oral cavity. Head Neck Surg 1982;5:22-8.

8. Terada T. Verrucous carcinoma of the oral cavity: A histopathologic study of 10 Japanese cases. J Maxillofac Oral Surg 2011;10:148-51.

9. Terada T. Squamous cell carcinoma arising within verrucous carcinoma of the oral cavity: A case report. Int J Clin Exp Pathol 2012;5:363-6.

10. Alkan A, Bulut E, Gunhan O, Ozden B. Oral verrucous carcinoma: A study of 12 cases. Eur J Dent 2010;4:202-7.

11. Available from: http://www.maxillofacialcenter.com/BondBook/ mucosa/verrucousca.html. [Last accessed on 2015 Jan 09].

12. Wu CF, Chen CM, Shen YS, Huang IY, Chen CH, Chen CY, et al. Effective eradication of oral verrucous carcinoma with continuous intraarterial infusion chemotherapy. Head Neck 2008;30:611-7.

13. Sheen MC, Sheu HM, Lai FJ, Lin SD, Wu CF, Wang YW, et al. A huge verrucous carcinoma of the lower lip treated with intra-arterial infusion of methotrexate. Br J Dermatol 2004;151:727-9.

14. Yeh CJ. Treatment of verrucous hyperplasia and verrucous carcinoma by shave excision and simple cryosurgery. Int J Oral Maxillofac Surg
2003;32:280-3.

15. Depprich RA, Handschel JG, Fritzemeier CU, Engers R, Kübler NR. Hybrid verrucous carcinoma of the oral cavity: A challenge for the clinician and the pathologist. Oral Oncol Extra 2006;42:85-90.

16. Carneiro TE, Marinho SA, Verli FD, Mesquita AT, Lima NL, Miranda JL. Oral squamous papilloma: Clinical, histologic and immunohistochemical analyses. J Oral Sci 2009;51:367-72.

17. Major T, Szarka K, Sziklai I, Gergely L, Czeglédy J. The characteristics of human papillomavirus DNA in head and neck cancers and papillomas. J Clin Pathol 2005;58:51-5.

18. Devi RS, Rajsekhar B, Srinivas GV, Moon NJ. Unusual length of pedicle: Pedunculated squamous papilloma of uvula causing unusual dysphagia of long duration in a child of 10 years. Case Rep Dent 2014;2014:313506.

19. Khalighi HR, Hamian M, Abbas FM, Farhadi S. Simultaneous existence of giant cell fibroma and squamous papilloma in the oral cavity. Indian J Med Specialities 2011;2:153-6.

20. Jaju PP, Suvarna PV, Desai RS. Squamous papilloma: Case report and review of literature. Int J Oral Sci 2010;2:222-5.

21. Goodstein LA, Khan A, Pinczewski J, Young VN. Symptomatic squamous papilloma of the uvula: Report of a case and review of the literature. Case Rep Otolaryngol 2012;2012:329289.

22. Pereira MC, Oliveira DT, Landman G, Kowalski LP. Histologic subtypes of oral squamous cell carcinoma: Prognostic relevance. J Can Dent Assoc 2007;73:339-44.

23. Neville BW, Day TA. Oral cancer and precancerous lesions. CA Cancer J Clin 2002;52:195-215.

24. Bouquot JE. Oral verrucous carcinoma. Incidence in two US populations. Oral Surg Oral Med Oral Pathol Oral Radiol Endod 1998;86:318-24.

25. Schwartz RA. Verrucous carcinoma of the skin and mucosa. J Am Acad Dermatol 1995;32:1-21.

26. Rajendran R, Sugathan CK, Augustine J, Vasudevan DM, Vijayakumar T. Ackerman's tumour (verrucous carcinoma) of the oral cavity: A histopathologic study of 426 cases. Singapore Dent J 1989;14:48-53.

27. Babaji P, Singh V, Chaurasia VR, Masamatti VS, Sharma AM. Squamous papilloma of the hard palate. Indian J Dent 2014;5:211-3.

28. Ghom A, Mhaske S. Textbook of Oral Pathology. $1^{\text {st }}$ ed. New Delhi, India: Jaypee Brothers Medical Publishers; 2009.

29. Garcia NG, Oliveira DT, Hanemann JA, Pereira AA. Oral verrucous carcinoma mimicking a chronic candidiasis: A case report. Case Rep Oncol Med 2012;2012:190272.

30. Asproudis I, Gorezis S, Aspiotis M, Tsanou E, Kitsiou E, Merminga E, et al. Orbital metastasis from verrucous carcinoma of the oral cavity: Case report and review of the literature. In Vivo 2007;21:909-12.

31. Batsakis JG, Hybels R, Crissman JD, Rice DH. The pathology of head and neck tumors: Verrucous carcinoma, Part 15. Head Neck Surg 1982;5:29-38.

32. Tanaka J, Yoshida K, Takahashi M, Suzuki M. A case of verrucous carcinoma of the tongue, effectively treated with preoperative chemotherapy (UFT, CDDP, PEP) and irradiation. Gan To Kagaku Ryoho 1992;19:525-7.

33. Karagozoglu KH, Buter J, Leemans CR, Rietveld DH, van den Vijfeijken S, van der Waal I. Subset of patients with verrucous carcinoma of the oral cavity who benefit from treatment with methotrexate. Br J Oral Maxillofac Surg 2012;50:513-8.

34. Chen HM, Chen CT, Yang H, Lee MI, Kuo MY, Kuo YS, et al. Successful treatment of an extensive verrucous carcinoma with topical 5-aminolevulinic acid-mediated photodynamic therapy. J Oral Pathol Med 2005;34:253-6.

35. Kato A, Takahashı Y, Yanohara K. Verrucous carcinoma of the tongue, a case report. Pract otorhinolaryngol 1991:84:775-80.

36. Dos Reis HL, Rabelo PC, de Santana MR, Ferreira DC, Filho AC. Oral squamous papilloma and condyloma acuminatum as manifestations of buccal-genital infection by human papillomavirus. Indian J Sex Transm Dis 2009;30:40-2.

\begin{tabular}{|l|l|}
\hline \multicolumn{2}{|c|}{ Access this article online } \\
\hline Quick Response Code: \\
\hline
\end{tabular}

